\title{
Polymerization of Oxetanes with Organoaluminium Catalysts. I. Kinetics of the Polymerization of 3-Methyl-3-chloromethyloxetane with the $i-\mathrm{Bu}_{3} \mathrm{Al}-\mathrm{H}_{2} \mathrm{O}$ Catalyst System
}

\author{
G. P. Aleksiuk, V. V. Shamanin, A. F. Podolsky, \\ L. V. Alferova, and V. A. KropacheV \\ Institute of Macromolecular Compounds, Academy of Sciences of the USSR, \\ Bolshoj 31, Leningrad, 199004, USSR.
}

(Received March 22, 1980)

\begin{abstract}
The kinetics of the polymerization of 3-methyl-3-chloromethyloxetane with the $i$ $\mathrm{Bu}_{3} \mathrm{Al}-\mathrm{H}_{2} \mathrm{O}$ catalyst system and the molecular-weight characteristics of the resulting polymer have been investigated. The main feature of this process is the ability for self-regulation of the size of the macromolecules with the formation of a polymer of high molecular weight $\left(\sim 10^{6}\right)$ and narrow molecular-weight distribution $\left(M_{w} / M_{n}=1.30 \pm 0.05\right)$ which do not depend on conversion and initial monomer and catalyst concentrations. A kinetic scheme for the polymerization involves a slow initiation stage, rapid propagation via the preliminary stage of monomer complexation with active centres, spontaneous monomolecular termination as a result of intramolecular interaction of the active centre with a fragment of its own polymer chain and the inhibition stage due to the deactivation of the unconsumed catalyst by the polymer. The mathematical description of this scheme enabled us to calculate the rate constants for elementary reactions of the process at $20^{\circ} \mathrm{C}$ : the propagation-rate constant is $(1.9 \pm 0.3) \times 10^{3} \mathrm{~min}^{-1}$; the initiation-rate constant is $(6.9 \pm 0.3) \times 10^{-4}$ $1 \mathrm{~mol}^{-1} \mathrm{~min}^{-1}$ and the termination-rate constant is $(0.16 \pm 0.02) \mathrm{min}^{-1}$.

KEY WORDS Polymerization Kinetics / Molecular Characteristics / 3Methyl-3-chloromethyloxetane / Organoaluminium Catalyst / Kinetic Scheme / Rate Constants / Elementary Reactions /
\end{abstract}

Among the polymerization processes of polar monomers much attention is being directed to the formation of heterochain polymers based on cyclic ethers. At the present the polymerization of cyclic ethers is being carried out with a wide variety of monomers differing in ring size and the number and nature of substituents. Polymers of oxetanes, fourmembered cyclic ethers, occupy an important place among polymers based on cyclic oxides. However, although these polymers arouse great interest, no systematic investigations of the mechanism of their polymerization are available in the literature. Only a series of papers of Penczek and co-workers ${ }^{1}$ should be mentioned.

These papers deal with the general kinetic relationships of the polymerization of 3,3bis(chloromethyl)oxetane (BCMO) with the $i$ $\mathrm{Bu}_{3} \mathrm{Al}-\mathrm{H}_{2} \mathrm{O}$ catalyst system, on the basis of which a kinetic scheme for the process has been proposed, the rate constants of elementary reactions have been determined and an attempt at discussing the chemistry of the stages of elementary reactions has been made. However, this process is very complex, being multistage, the mechanism of initiation is not clear and the solubility of the resultant polymer is limited. Thus, on the basis of kinetic data alone without any statistical analysis of the process and the precise establishment of the role played by water, it is impossible to say with confidence whether the mechanism of the process proposed by Penczek and co-workers is correct. This is the reason for the present investigation.

3-Methyl-3-chloromethyloxetane (MCMO) was chosen for investigation since its polymers, unlike those of BMCO, are readily soluble in many organic solvents. This made it possible to carry out the investigation of the kinetics of polymerization under mild homogeneous conditions over a wide range of 
initial monomer $\left(m_{0}\right)$ and catalyst $\left(n_{0}\right)$ concentrations and to use various methods for the study of molecular-weight characteristics of the polymer. The system, $i-\mathrm{Bu}_{3} \mathrm{Al}-\mathrm{H}_{2} \mathrm{O}$ was used as a catalyst since organoaluminium compounds are known to be the most effective catalysts for the polymerization of oxetanes. Chlorobenzene was considered to be the most suitable solvent for studying the kinetics of polymerization, since it ensures a relatively low viscosity of the medium during polymerization, its polarity is comparable to that of the monomer, it undergoes no specific solvation, and it is readily freed from water. These properties permit the exclusion of the effect of the changing monomer-solvent ratio during polymerization on polymerization kinetics.

There has been much uncertainty and contradictions as to the mechanism of the catalysis in the $\mathrm{AlR}_{2}-\mathrm{H}_{2} \mathrm{O}$ systems. There is not even a common opinion as to the optimum (with respect to the yield and rate of polymerization) molar ratio of alkylaluminium to water in the catalyst system and the method for preparing the catalyst; that is the hydrolysis of $\mathrm{AlR}_{3}$ should be carried out in the presence of the monomer or in its absence. Our experimental checking has shown ${ }^{2}$ that the system prepared in the absence of the monomer in the ratio of $\mathrm{AlR}_{3}: \mathrm{H}_{2} \mathrm{O}=2.0$ exhibits a maximum catalytic activity. This does not agree with the data in ref 1 $\left(\mathrm{AlR}_{3} / \mathrm{H}_{2} \mathrm{O}_{\text {optim. }}=1.0\right)$ and ref $3\left(\mathrm{AlR}_{3} / \mathrm{H}_{2} \mathrm{O}_{\text {optim. }}=\right.$ 1.5). However, the character of the effect of the change in the $\mathrm{AlR}_{3}: \mathrm{H}_{2} \mathrm{O}$ ratio on the kinetics of the process is the same as in ref 1 , meaning that an increase in water concentration in excess of the optimum ratio leads to a decrease in the catalytic activity up to its complete disappearance at the equimolar $\mathrm{AlR}_{3}: \mathrm{H}_{2} \mathrm{O}$ ratio. However, an increase in the $\mathrm{AlR}_{3}$ contents in excess of the optimum ratio does not affect the kinetics of the process. Our investigation of the mechanism of hydrolysis of $i-\mathrm{Bu}_{3} \mathrm{Al}$ under model conditions and the data on the effect of the $A l R_{3} / \mathrm{H}_{2} \mathrm{O}$ ratio on the kinetics of the process $^{2}$ suggest that, in the polymerization of $\mathrm{MCMO}$ with the $i-\mathrm{Bu}_{3}$ : $\mathrm{H}_{2} \mathrm{O} \geqq 2.0$ catalyst system, bis(diisobutylaluminium)oxane, the main product of hydrolysis under these conditions, is the catalyst and the hydrolysis process can be described by the following general equation.

$$
\begin{aligned}
n \mathrm{AlR}_{3}+ & m \mathrm{H}_{2} \mathrm{O} \longrightarrow m\left(\mathrm{R}_{2} \mathrm{Al}\right)_{2} \mathrm{O} \\
& +2 m \mathrm{RH}+(n-2 m) \mathrm{AlR}_{3}
\end{aligned}
$$

where " $n$ " is greater than or equal to $2 m$.

This equation shows that the concentration of alumoxane being formed is equal to that of the water present in the system and both active hydrogen atoms are consumed in the formation of gaseous products which are removed from the reactor before the introduction of the monomer. Our data are in good agreement with the concepts of the role played by water and the mechanism of incomplete hydrolysis of $\mathrm{AlR}_{3}{ }^{4,5}$

\section{EXPERIMENTAL}

\section{Materials}

3-Methyl-3-chloromethyloxetane was synthesized by a published method. ${ }^{6}$ A chromatographically pure fraction with bp $56^{\circ} \mathrm{C}$ at $23 \mathrm{mmHg}$ was used for further operations. Since the monomer investigated had not been described in the literature, we determined its main characteristics (in a benzene solution at $20^{\circ} \mathrm{C}$ ): $n_{\mathrm{D}}=1.451 ; \rho=1.0927 ; R=29.69$; $\varepsilon_{0}=2.284 ; V_{0}=1.1372 ; \mu_{\mathrm{ef}}=1.95$, where $n_{\mathrm{D}}$ is the refractive index, $\rho$ is the density, $R$ is the molar refraction, $\varepsilon_{0}$ is the dielectric permittivity, $V_{0}$ is the specific volume of solution at infinite dilution and $\mu_{\mathrm{ef}}$ is the dipole moment.

The Debye method of dilute solutions was used to determine the dipole moment of the monomer. ${ }^{7}$ It consists in the extrapolation of concentration dependences of dielectric permittivity and specific volume to infinite dilution. The dipole moment was calculated according to the equations:

$$
\begin{aligned}
\mu_{\mathrm{ef}} & =0.0128\left\{\left(R_{2 \infty}-R\right) T\right\}^{1 / 2} \\
P_{2 \infty} & =\frac{3 \alpha V_{0}}{\left(\varepsilon_{0}+2\right)^{2}} \times M+\left(V_{0}+\beta\right) \frac{\varepsilon_{0}-1}{\varepsilon_{0}+2} \times M
\end{aligned}
$$

where $P_{2 \infty}$ is the molar polarization of the polar component of the solution at infinite dilution and $\alpha=\left(\mathrm{d} \varepsilon / \mathrm{d} W_{2}\right)_{W_{2}=0}$ and $\beta=(\mathrm{d} V / \mathrm{d} W)_{W_{2}=0}$ are tangents of the slopes of the dielectric permittivity and specific volume of solution $v s$. weight concentration.

Commercial $i-\mathrm{Bu}_{3} \mathrm{Al}$ was purified by vacuum distillation, using the fraction distilled at $47^{\circ} \mathrm{C}(1$ $\mathrm{mmHg}$ ). Pure $i-\mathrm{Bu}_{3} \mathrm{Al}$ was used for polymerization by vacuum condensation from a microdosimeter in reactor. 


\section{Procedure}

Polymerization kinetics were studied dilatometrically in two-chamber dilatometers under conditions excluding water, air, and oxygen. The residual concentration of water in the reaction mixture was determined kinetically ${ }^{1}$ and electrometrically. Water in the form of an aqueous solution of chlorobenzene was introduced with a syringe in a stream of dry purified argon. Other components of the reaction mixture were introduced by vacuum condensation. The polymer was precipitated into methanol and conversion was determined from polymer yield with a simultaneous chromatographic check on the residual monomer in the precipitating mixture. The method of polymerization has been described in detail previously. ${ }^{8}$

Poly(MCMO) is an amorphous rubbery white polymer having a glass-transition temperature of $-38^{\circ} \mathrm{C}$. It is soluble in many organic solvents such as aromatic hydrocarbons, tetrahydrofuran (THF), dimethyl sulphoxide, methyl ethyl ketone, dichloromethane, and dichloroethane. It is not soluble in water, alcohols, and ethers. The specific gravity of poly(MCMO) $\left(\rho^{20}\right)$ is $1.184 \pm 0.006$ and its refractive index $\left(n_{\mathrm{D}}^{20}\right)$ is $1.48 \pm 0.005$.

\section{RESULTS AND DISCUSSION}

\section{Main Features of the Polymerization Process}

Figure 1 shows typical kinetic time-conversion curves obtained at various temperatures and $n_{0}$ values, and having a distinct $S$-line shape. Each of these curves has three different parts: in the beginning of the process the rate increases gradually, a linear portion then follows and subsequently the curve deviates to the right of the linear portion, indicating that the process has slowed down. It is clear that as $n_{0}$ decreases, a decrease in the polymerization rate occurs in the earlier stages of polymerization. Moreover, this decrease is much higher than that due to the monomer consumption alone. The length of the initial part which can be regarded as the induction period is mainly determined by the temperature of the process and its dependence on $m_{0}$ and $n_{0}$ is slight. The overall activation energy of polymerization calculated from the slope of the plot of $\log R_{\mathrm{p}} v s .1 / T$ is $11.6 \pm 0.3$ $\mathrm{kcal} \mathrm{mol}{ }^{-1}\left(R_{\mathrm{p}}\right.$ is the polymerization rate and $T$ is the temperature of the process). The dependence of the initial polymerization rate on $m_{0}$ is linear and in

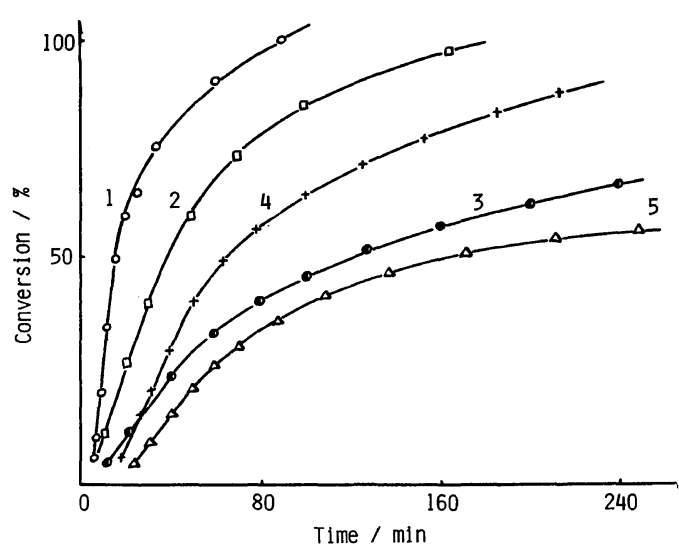

Figure 1. Kinetic curves of MCMO polymerization with the $i-\mathrm{Bu}_{3} \mathrm{Al}-\mathrm{H}_{2} \mathrm{O}$ catalyst system at different $\left[\mathrm{H}_{2} \mathrm{O}\right]$ and temperatures. Curves $1-3:\left[\mathrm{M}_{0}\right], 0.5 \mathrm{~mol} \mathrm{1}^{-1} ;[i$ $\left.\mathrm{Bu}_{3} \mathrm{Al}\right], 0.02 \mathrm{moll}^{-1} ; 10^{\circ} \mathrm{C}$. $\left[\mathrm{H}_{2} \mathrm{O}\right] \times 10^{2} \mathrm{moll}^{-1}: 1,0.9 ; 2$, 0.33; 3, 0.096. Curves 4-5: $\left[\mathrm{M}_{0}\right], 0.5 \mathrm{~mol} \mathrm{l}^{-1} ;\left[i-\mathrm{Bu}_{3} \mathrm{Al}\right]$, $0.03 \mathrm{~mol} \mathrm{l}^{-1} ;\left[\mathrm{H}_{2} \mathrm{O}\right], 0.7 \times 10^{2} \mathrm{~mol} \mathrm{l}^{-1} ; T /^{\circ} \mathrm{C}: 4,0 ; 5$, -9.0 .

the initial stage the polymerization is of the first order in the monomer.

Experimental data on the change in molecularweight characteristics of the polymer with conversion were of great interest and very unusual. The data in Table II show that the number-average molecular weight $\left(M_{n}\right)$ attains high values even at a conversion $(x)$ of $4.6 \%$ and does not change further up to the completion of polymerization. The parameters of polydispersity do not change with conversion either. In this case, the experimental values of $M_{n}$ are 600 to 700 -fold higher than the corresponding calculated values. This shows that in the initiation the degree of consumption of the catalyst is very low. Data in Table I show that the active center very rapidly increases in size and undergoes decay, the lifetime of each macromolecule being much shorter than the time of the entire process. At any time, the concentration of active centres is very low, having an order of magnitude of $10^{-6} \mathrm{~mol} \mathrm{l}^{-1}$. Hence, it may be assumed that each macromolecule is formed at a constant concentration of the monomer, indicating that the process is quasi-stationary. Doubtless, the independence of $M_{n}$, polydispersity of $(x)$, and the low efficiency of the consumption of the catalyst show that the polymerization of MCMO proceed by at least three elementary reactions: initiation, pro- 
Table I. Dependence of molecular-weight characteristics of poly(MCMO) on conversion ${ }^{\mathrm{a}}$

\begin{tabular}{|c|c|c|c|c|c|c|c|c|}
\hline \multirow{2}{*}{ No. } & Conversion & $\begin{array}{c}\text { Osmo- } \\
\text { metry } \\
\text { data }\end{array}$ & \multicolumn{6}{|c|}{ Data on high-speed sedimentation } \\
\hline & $\%$ & $M_{n} \times 10^{-3}$ & $M_{n} \times 10^{-3}$ & $M_{w} / M_{n}$ & $M_{z} / M_{w}$ & $\frac{S_{0}}{S_{\mathrm{v}}}$ & $M_{\mathrm{SD}} \times 10^{-3}$ & $\sigma_{\mathrm{s}} / S$ \\
\hline 1 & 4.6 & 610 & 820 & 1.29 & 1.23 & 26 & 1000 & 0.25 \\
\hline 2 & 21.6 & 720 & 720 & 1.30 & 1.23 & 26 & 1000 & 0.27 \\
\hline 3 & 45.8 & 700 & 820 & 1.30 & 1.22 & 26 & 1000 & 0.24 \\
\hline 4 & 89.0 & 760 & 820 & 1.27 & 1.24 & 23 & 810 & 0.20 \\
\hline
\end{tabular}

a The method for calculating the values $M_{w} / M_{n} ; M_{z} / M_{w} ; M_{\mathrm{SD}} ; \sigma_{\mathrm{s}} / S$ ensured the precision within 12.0 to $15.0 \%$. Initial conditions: $\left[\mathrm{M}_{0}\right], 0.55 \mathrm{~mol} \mathrm{l}^{-1}\left[\mathrm{H}_{2} \mathrm{O}\right], 0.003 \mathrm{~mol} \mathrm{l}^{-1} ;\left[i-\mathrm{Bu}_{3} \mathrm{Al}\right], 0.01 \mathrm{~mol} \mathrm{l}^{-1}$; a chlorobenzene solution, $20^{\circ} \mathrm{C}$.

Table II. Dependence of molecular weight of poly(MCMO) on the starting conditions of polymerization $(x=0.55 \pm 0.05)$

\begin{tabular}{|c|c|c|c|c|}
\hline$m_{0}$ & $\mathrm{H}_{2} \mathrm{O} \times 10^{3}$ & $i-\mathrm{Bu}_{3} \mathrm{Al}$ & $\mathrm{T}$ & $M \times 10^{-3}$ \\
\hline $\operatorname{mol~1} 1^{-1}$ & $\operatorname{mol~1}{ }^{-1}$ & $\mathrm{~mol} \mathrm{l}^{-1}$ & ${ }^{\circ} \mathrm{C}$ & \\
\hline 0.3 & 6.0 & 0.03 & 20 & 700 \\
\hline 0.7 & 6.0 & 0.03 & 20 & 740 \\
\hline 1.2 & 6.0 & 0.03 & 20 & 680 \\
\hline 0.5 & 0.96 & 0.02 & 10 & 560 \\
\hline 0.5 & 3.35 & 0.02 & 10 & 520 \\
\hline 0.5 & 9.95 & 0.02 & 10 & 520 \\
\hline 0.5 & 6.0 & 0.03 & 20 & 650 \\
\hline 0.5 & 6.0 & 0.03 & 0 & 750 \\
\hline 0.5 & 6.0 & 0.03 & -20 & 910 \\
\hline
\end{tabular}

pagation, and limitation of propagation.

The value of $M_{n}$ is also independent of $n_{0}$ and $m_{0}$, and increases slightly with a decrease in the temperature of the process.

We also established that the addition of a new monomer portion following polymerization does not lead to the renewal of the process. If the low degree of consumption of the catalyst in the initiation stage is taken into account, this fact can be considered to indicate that the polymer being formed deactivates the unconsumed catalyst. Hence, the observed decrease in the polymerization rate during the process, which is not equivalent to monomer consumption, should be due to the deactivation of the catalyst by the polymer. This deactivation increases with conversion and with a decrease in the initial concentration of the catalyst. This is confirmed by the inhibiting action of the addition of catalytic portions of diethyl ether which can be considered as a low-molecular model of the monomer unit of the polymer chain. ${ }^{9}$ The effect of adding low-molecular ethers has already been reported. ${ }^{1}$

Evidently, apart from inhibition, the possibility of an interaction of the polymer with active centres should also be taken into account. At present, such an interaction due to the presence of reactive oxygen atoms in the chain is well known. ${ }^{10}$ Recently this reaction has been included in the kinetic scheme of the polymerization of $\mathrm{BCMO}$ and has been considered as a terminating reaction. ${ }^{1}$

It should be taken into account that both interand intra-molecular reactions can take place. We feel that in the case investigated by us, intramolecular reactions dominate since otherwise it would be impossible to explain the independence of $M_{n}$, polydispersity of $(x)$, and the narrow molecularweight distribution (MWD). ${ }^{11,12}$ The probability of intramolecular interaction of active centres with their own polymer chain does not depend on the concentration of the monomer $\left(m_{0}\right)$ and the polymer, and $M_{n}$, and polydispersity do not depend on $m_{0}, n_{0}$, and conversion. Hence, it should be assumed that the probability of propagation is also independent of $m_{0}$ and $n_{0}$. It thus follows that 
propagation proceeds via the preliminary formation of the complex of the active centre with the monomer. This provides an explanation for the first-order polymerization rate in the monomer in the initial stage of the process. By no other assumptions can the experimental data be explained. For example, if it is assumed that complexation occurs rapidly in the initiation stage, the first-order rate in the monomer is retained $\left(\mathrm{d} R^{*} / \mathrm{d} t=k_{\mathrm{i}} n_{0}-k_{\mathrm{t}} R^{*}\right.$ where $R^{*}$ is the concentration of active centres. In the stationary part we have $R^{*}=k_{\mathrm{i}} n_{0} / k_{\mathrm{t}}$. Hence, $-\mathrm{d} m / \mathrm{d} t=k_{\mathrm{p}} k_{\mathrm{i}} n_{0} m / k_{\mathrm{t}}$, i.e., the first-order rate in the monomer is retained). However, the number-average degree of polymerizatior roportional to the ratio of the average probr ${ }^{-}$. 1 ties of propagation and termination depends on conversion $\left(\bar{P}_{n} \sim \bar{W}_{\mathrm{p}} / W_{\mathrm{t}}=k_{\mathrm{p}} \bar{m} / k_{\mathrm{t}}=f(x)\right)$.

It can be shown in a similar manner that when complexation proceeds rapidly in both the initiation and propagation stages, it is possible to obtain the independence of $P_{n}$ of $(x)$ but the polymerization rate will be of the zero order in the monomer. On the other hand, although the assumption that the limitation of chain propagation proceeds with participation of the monomer leads to the first order in the monomer (if initiation and propagation occur without the preliminary complexation stage), it does not provide the possibility of describing the experimental dependences $x=F(t)$.

The analysis of our experimental data shows that the observed limitation of chain propagation is brought on by the intramolecular interaction of active centres with their own polymer chain, and this 'can be considered as spontaneous monomolecular termination. Hence, the polymerization of MCMO with the $i-\mathrm{Bu}_{3} \mathrm{Al}-\mathrm{H}_{2} \mathrm{O}$ catalyst system comprises slow initiation, rapid propagation via preliminary complexation of active centres with the monomer, spontaneous monomolecular termination, and the stage of deactivation of the catalyst by the polymer.

\section{DERIVATION OF EQUATION OF THE POLYMERIZATION KINETICS}

In terms of formal kinetics, the entire-polymerization process may be represented by the following scheme.

Formation of active polymerization centres,

$$
\begin{array}{lll}
\mathrm{C}+\mathrm{M} \underset{k_{-\mathrm{i}}^{\prime}}{\stackrel{k_{\mathrm{i}}^{\prime}}{\rightleftarrows}} \mathrm{C}: \mathrm{M} & \stackrel{k_{\mathrm{i}}^{\prime \prime}}{\longrightarrow} & \mathrm{R}^{*} \\
\left(n_{1}\right)(m) & \left(n_{2}\right) & \left(n_{3}\right)
\end{array}
$$

Propagation of polymer chains,

$$
\mathrm{R}^{*}+\mathrm{M} \underset{k_{-\mathrm{p}}^{\prime}}{\stackrel{k_{\mathrm{p}}^{\prime}}{\rightleftarrows}} \mathrm{R}_{\left(n_{4}\right)}^{\stackrel{k_{\mathrm{p}}^{\prime \prime}}{\longrightarrow}} \mathrm{R}^{*}
$$

Limitation of chain propagation,

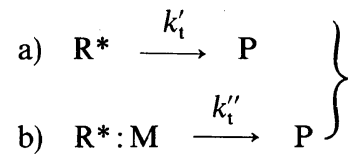

Inactivation of the catalyst by the polymer,

$$
\mathrm{C}+\mathrm{P} \underset{k_{\mathrm{dsc}}}{\stackrel{k_{\mathrm{sc}}}{\rightleftarrows}} \mathrm{C}: \mathrm{P}\left(n_{\mathrm{sc}}\right)
$$

where $k_{\mathrm{sc}}$ and $k_{\mathrm{dsc}}$ are the constants of screening and descreening of the catalyst by the polymer.

Complexation in the initiation stage is introduced on the basis of the unity of the concepts of the mechanisms of initiation and propagation. Since complexation does not become evident in the kinetics, the relationship $n_{2} \ll n_{1}$ should be valid regardless of conversion $(x)$.

This scheme of elementary reactions may be described by the following system of differential equations.

$\mathrm{d} n_{\mathrm{sc}} / \mathrm{d} t=k_{\mathrm{sc}} n_{1}\left(m_{0}-m\right)-k_{\mathrm{dsc}} n_{\mathrm{sc}}$

$\mathrm{d} n_{1} / \mathrm{d} t=-k_{\mathrm{sc}} n_{1}\left(m_{0}-m\right)+k_{\mathrm{dsc}} n_{\mathrm{sc}}-k_{\mathrm{i}}^{\prime} n_{1} m+k_{-\mathrm{i}}^{\prime} n_{2}$

$\mathrm{d} n_{2} / \mathrm{d} t=k_{\mathrm{i}}^{\prime} n_{1} m-\left(k_{-\mathrm{i}}^{\prime}+k_{\mathrm{i}}^{\prime \prime}\right) n_{2}$

$\mathrm{d} n_{3} / \mathrm{d} t=k_{\mathrm{i}}^{\prime \prime} n_{2}-k_{\mathrm{p}}^{\prime} m n_{3}+\left(k_{-\mathrm{p}}^{\prime}+k_{\mathrm{p}}^{\prime \prime}\right) n_{4}-k_{\mathrm{t}}^{\prime} n_{3}$

$\mathrm{d} n_{4} / \mathrm{d} t=k_{\mathrm{p}}^{\prime} m n_{3}-\left(k_{-\mathrm{p}}^{\prime}+k_{\mathrm{p}}^{\prime \prime}\right) n_{4}-k_{\mathrm{t}}^{\prime \prime} n_{4}$

$\mathrm{d} P / \mathrm{d} t=k_{\mathrm{t}}^{\prime} n_{3}+k_{\mathrm{t}}^{\prime \prime} n_{4}$

$-\mathrm{d} m / \mathrm{d} t=k_{\mathrm{p}}^{\prime \prime} n_{4}$

Equations $1-7$ are a system of nonlinear differential equations and have no precise analytical solution. However, the polymerization we investigated exhibits all the properties of a "quasistationary" process. The condition that complexation is manifested kinetically in the propagation stage leads to $n_{4} \gg n_{3}$. This relationship 
holds only when the intensity of the $n_{3} \rightarrow n_{4}$ transitions is much higher than that of the $n_{2} \rightarrow n_{3}$ and $n_{3}, n_{4} \rightarrow P$ transitions. Hence, it may be assumed that during polymerization, the following relationship between the current concentrations of active centres is valid.

$$
n_{3}=\frac{k_{-\mathrm{p}}^{\prime}+k_{\mathrm{p}}^{\prime \prime}}{k_{\mathrm{p}}^{\prime} m} n_{4}
$$

Since induction period $\left(t_{\text {ind }}\right)$ is small, i.e., the rate of monomer consumption and the concentration of active centres are rapidly stabilized, it follows that during almost the entire process, the following relationship is valid.

$$
k_{\mathrm{i}}^{\prime \prime} n_{2} \approx k_{\mathrm{t}}^{\prime} n_{3}+k_{\mathrm{t}}^{\prime \prime} n_{4}
$$

Substitution of the value of $n_{3}$ from eq 8 into eq 9 gives

$$
k_{\mathrm{i}}^{\prime \prime} n_{2} \approx k_{\mathrm{t}}^{\prime \prime}\left[1+\frac{k_{\mathrm{t}}^{\prime}}{k_{\mathrm{t}}^{\prime \prime}} \frac{k_{-\mathrm{p}}^{\prime}+k_{\mathrm{p}}^{\prime \prime}}{k_{\mathrm{p}}^{\prime} m}\right] n_{4} .
$$

It follows from eq 7 and 10 that the rate of monomer consumption is stabilized at the moment of the stabilization of concentration $n_{2}$ and, hence, $\mathrm{d} n_{2} / \mathrm{d} t=0$. Then, eq 3 gives

$$
n_{2}=\frac{k_{\mathrm{i}}^{\prime} m}{k_{-\mathrm{i}}^{\prime}+k_{\mathrm{i}}^{\prime \prime}} n_{1} \text {. }
$$

Substitution of the value of $n_{2}$ into eq 10 gives

$$
k_{\mathrm{i}} m n_{1}=k_{\mathrm{t}}^{\prime \prime}\left[1+\frac{k_{\mathrm{t}}^{\prime}}{k_{\mathrm{t}}^{\prime \prime}} \frac{k_{-\mathrm{p}}^{\prime}+k_{\mathrm{p}}^{\prime \prime}}{k_{\mathrm{p}}^{\prime} m}\right] n_{4}
$$

where $k_{\mathrm{i}}=k_{\mathrm{i}}^{\prime} k_{\mathrm{i}}^{\prime \prime} /\left(k_{-\mathrm{i}}^{\prime}+k_{\mathrm{i}}^{\prime \prime}\right)$.

Let us assume that the intensity of exchange transitions $n_{1} \rightarrow n_{\mathrm{sc}}$ is also higher than the initiation rate $n_{1} \rightleftarrows n_{2} \rightarrow n_{3}$ equal to $k_{\mathrm{i}} n_{1} m$, i.e., that $n_{1}$ and $n_{\mathrm{sc}}$ are related to each other (with the exception of the induction period) by the condition (from eq 1):

$$
n_{\mathrm{sc}}=\frac{k_{\mathrm{sc}}\left(m_{0}-m\right)}{k_{\mathrm{dsc}}} n_{1} .
$$

The condition of the balance of catalyst consumption gives, $n_{0}=n_{\mathrm{sc}}+n_{1}+n_{2}+n_{3}+n_{4}+P$. If the low rate of catalyst consumption and the condition $n_{2} \ll n_{1}$ are taken into account, the balance equation is given by $n_{0}=n_{\mathrm{sc}}+n_{1}$.

Equation 13 gives,

$$
n_{1}=\frac{n_{0}}{1+\frac{k_{\mathrm{sc}}\left(m_{0}-m\right)}{k_{\mathrm{dsc}}}} .
$$

Substitution of this expression into eq 12 gives,

$$
n_{4}=\frac{k_{\mathrm{i}} n_{0} m}{k_{\mathrm{t}}^{\prime \prime}\left[1+\frac{k_{\mathrm{t}}^{\prime}}{k_{\mathrm{t}}^{\prime \prime}} \frac{k_{-\mathrm{p}}^{\prime}+k_{\mathrm{p}}^{\prime \prime}}{k_{\mathrm{p}}^{\prime} m}\right]\left[1+\frac{k_{\mathrm{sc}}}{k_{\mathrm{dsc}}}\left(m_{0}-m\right)\right]} .
$$

At relatively high values of $(x)$, since $k_{\mathrm{sc}} \gg k_{\mathrm{dsc}}$, we have,

$$
n_{4} \approx \frac{k_{\mathrm{i}} k_{\mathrm{dsc}} n_{0} m}{k_{\mathrm{t}}^{\prime \prime} k_{\mathrm{sc}}\left(m_{0}-m\right)\left[1+\frac{k_{\mathrm{t}}^{\prime}}{k_{\mathrm{t}}^{\prime \prime}} \frac{k_{-\mathrm{p}}^{\prime}+k_{\mathrm{p}}^{\prime \prime}}{k_{\mathrm{p}}^{\prime} m}\right]} .
$$

Hence, the polymerization rate is determined by the equation,

$$
-\frac{\mathrm{d} m}{\mathrm{~d} t}=\frac{k_{\mathrm{p}}^{\prime \prime} k_{\mathrm{i}} k_{\mathrm{dsc}} n_{0} m}{k_{\mathrm{t}}^{\prime \prime} k_{\mathrm{sc}}\left(m_{0}-m\right)\left[1+\frac{k_{\mathrm{t}}^{\prime}}{k_{\mathrm{t}}^{\prime \prime}} \frac{k_{-\mathrm{p}}^{\prime}+k_{\mathrm{p}}^{\prime \prime}}{k_{\mathrm{p}}^{\prime} m}\right]} .
$$

The following symbols are now introduced.

$$
a \equiv \frac{k_{\mathrm{t}}^{\prime}}{k_{\mathrm{t}}^{\prime \prime}} \frac{k_{-\mathrm{p}}^{\prime}+k_{\mathrm{p}}^{\prime \prime}}{k_{\mathrm{p}}^{\prime}} ; \quad b \equiv \frac{k_{\mathrm{p}}^{\prime \prime} k_{\mathrm{i}} k_{\mathrm{dsc}}}{k_{\mathrm{t}}^{\prime \prime} k_{\mathrm{sc}}} .
$$

Following the insertion of $a$ and $b$, eq 14 becomes,

$$
-\frac{\mathrm{d} m}{\mathrm{~d} t}=\frac{b n_{0} m}{\left(m_{0}-m\right)\left(1+\frac{a}{m}\right)} .
$$

When the reduced polymerization time ${ }^{13}$

$$
\varphi=\int_{0}^{t} m(t) \mathrm{d} t
$$

is introduced, eq 15 becomes,

$$
\frac{\mathrm{d} x}{\mathrm{~d} \varphi}=\frac{b m_{0}}{m_{0}^{2} x\left[1+\frac{a}{m_{0}(1-x)}\right]} .
$$

Integration of eq 16 gives,

$$
\begin{aligned}
\varphi-\varphi_{\text {ind }}= & \frac{m_{0}\left(a+m_{0}\right)}{2 b n_{0}} x^{2} \\
& +\frac{a}{b} \frac{m_{0}}{n_{0}}\left[\ln \frac{1}{1-x}-x-\frac{x^{2}}{2}\right] .
\end{aligned}
$$

Equation 17 shows that the kinetic curves in the $x^{2}-\varphi$ coordinate system should become linear at low values of $(x)$. The second term on the right-hand side of eq 17 takes into account the deviation from the linear portion at high values of $(x)$. The analysis of eq 17 shows that the degree of linearity of the 
kinetic curves depends on $m_{0}$ but not on $n_{0}$. At the same value of $n_{0}$ when $m_{0}$ increases, the curves should become straighter up to high values of $(x)$.

If eq 17 is used, it is possible to determine the preliminary values of $a$ and $b$ from the slope of the linear kinetic curves in the $x^{2}-\varphi$ coordinate system. Should it be necessary, the values obtained may be corrected by trial- and error-method. It is difficult to indicate more general methods for solving this problem since it is included in the class of problems of nonlinear optimization which at the present, have no simple solutions. For kinetic curves obtained in the polymerization of MCMO at $20^{\circ} \mathrm{C}$, the use of this method permitted the selection of the values of $a=0.244$ and $b=1.330$, which are in satisfactory agreement with the experimental kinetic curves (Figure 2a).

If the corresponding transformations of eq 15 are carried out, the equation for the polymerization rate in the $x-t$ system of coordinates is obtained as,

$$
t-t_{\text {ind }}=\frac{m_{0}-a}{b n_{0}} \ln \frac{1}{1-x}+\frac{a}{b n_{0}} \frac{x}{1-x}-\frac{m_{0}}{b n_{0}} x .
$$

Figure $2 \mathrm{~b}$ shows the curves for the polymerization of MCMO calculated according to eq 18 by using the $a$ and $b$ constants. These calculated curves are in good agreement with experimental dependences.

Hence, although this scheme is complex and includes a large number of constants, the polymerization is described satisfactorily by relatively simple equations 17 and 18. The form of these equations shows that the shape of kinetic curves is described only by four parameters: $m_{0}, n_{0}$, and two constants $a$ and $b$ common to all kinetic curves obtained at a constant temperature. Good agreement between the calculated curves and experimental results shows that our scheme for the polymerization of MCMO with a complex-catalyst system $i-\mathrm{Bu}_{3} \mathrm{Al}-\mathrm{H}_{2} \mathrm{O}$ is valid.

\section{DETERMINATION OF RATE CONSTANTS FOR ELEMENTARY REACTIONS}

\section{Initiation Stage}

The number of active centres appearing during the time $\mathrm{d} t$ is determined by the equation $\mathrm{d} n=k_{\mathrm{i}} n_{0} m \mathrm{~d} t$. After integration and averaging over the induction period, it was determined that $n=k_{\mathrm{i}} n_{0}\left[\varphi(t)-\left(\varphi_{\text {ind }} / 2\right)\right]$ active centres were formed
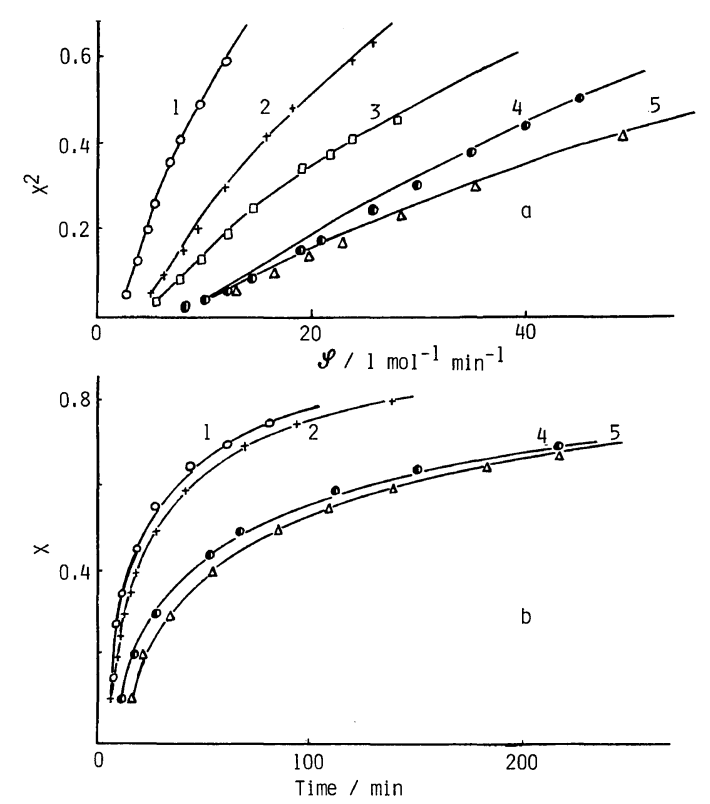

Figure 2. Conversion $(x)$ vs. reduced time $(\varphi)$ in coordinate systems $x^{2}-\varphi$ (a) and time (b) for the polymerization of $\mathrm{MCMO}$ in a chlorobenzene solution at $20^{\circ} \mathrm{C}$ by the action of the $i-\mathrm{Bu}_{3} \mathrm{Al}-\mathrm{H}_{2} \mathrm{O}$ system at the following values of $\left[\mathrm{H}_{2} \mathrm{O}\right] \times 10^{-3},\left[i-\mathrm{Bu}_{3} \mathrm{Al}\right] \times 10^{-2},\left[\mathrm{M}_{0}\right]$, respectively (in $\mathrm{mol} \mathrm{l}^{-1}$ ): $1,6.0 ; 3.0 ; 0.3,2,6.0 ; 3.0 ; 0.5,3$, $1.5 ; 1.0 ; 0.273,4,3.0 ; 2.0 ; 0.55$, and $5,2.0 ; 1.0 ; 0.53$; at $20^{\circ} \mathrm{C}$. Points correspond to experimental data and the lines represent calculated data.

during the time $t$. This expression gives the total number of polymer chains formed during the time $t$. On the other hand, the total number of chains may be determined by the equation $n=m_{0} x(t) / \bar{P}_{n}(t)$.

Hence,

$$
k_{\mathrm{i}}=\frac{m_{0} x(t)}{P_{n}(t) n_{0}\left[\varphi(t)-\varphi_{\text {ind }} / 2\right]} .
$$

The values of $k_{\mathrm{i}}$ were calculated using the values of $x=0.30$.

\section{Stage of the Limitation of Chain Propagation}

In accordance with the scheme shown above, at $t \leqq t_{\text {ind }}$ we have,

$$
\mathrm{d} R^{*} / \mathrm{d} t=k_{\mathrm{i}} n_{0} m_{0}-k_{\mathrm{t}}^{\prime} n_{3}-k_{\mathrm{t}}^{\prime \prime} n_{4} .
$$

The substitution of the value of $n_{3}$ gives,

$$
\frac{\mathrm{d} R^{*}}{\mathrm{~d} t}=k_{\mathrm{i}} n_{0} m_{0}-k_{\mathrm{t}}^{\prime \prime}\left[1+\frac{k_{\mathrm{t}}^{\prime}}{k_{\mathrm{t}}^{\prime \prime}} \frac{k_{-\mathrm{p}}^{\prime}+k_{\mathrm{p}}^{\prime \prime}}{k_{\mathrm{p}}^{\prime} m_{0}}\right] n_{4} .
$$


Taking into account that $R^{*}=n_{3}+n_{4}$ and $n_{4} \gg n_{3}$, we have,

$$
\mathrm{d} n_{4} / \mathrm{d} t=k_{\mathrm{i}} n_{0} m_{0}-k_{\mathrm{t}}^{\prime \prime}\left[1+a / m_{0}\right] n_{4} .
$$

The solution of this equation leads to the dependence,

$$
n_{4}=\frac{k_{\mathrm{i}} n_{0} m_{0}}{k_{\mathrm{t}}^{\prime \prime}\left[1+\frac{a}{m_{0}}\right]}\left\{1-\exp \left[-k_{\mathrm{t}}^{\prime \prime}\left(1+\frac{a}{m_{0}}\right) t\right]\right\} .
$$

Analysis of this equation shows that $n_{4}$ is stabilized when the term $\mathrm{e}^{-k_{i}^{\prime \prime}\left(1+a / m_{0}\right) t} \ll 1$ is much less than unity. Since the stabilization of active centres $\left(n_{4}\right)$ occurs at the end of the induction period, it follows that, $k_{\mathrm{t}}^{\prime \prime}\left(1+a / m_{0}\right) \approx 1 / t_{\text {ind }}=m_{0} / \varphi_{\text {ind }}$ and, hence,

$$
k_{\mathrm{t}}^{\prime \prime}=\frac{m_{0}}{\varphi_{\text {ind }}\left(1+a / m_{0}\right)} .
$$

\section{Propagation Stage}

The propagation-rate constant can be determined according to eq 17 from the slope of the stationary part of the kinetic curve $x=F(\varphi)$. The quasi-linear part corresponds to the stabilized state in which, as already shown, the concentration of active centres is determined by the equation,

$$
n_{4}=\frac{k_{\mathrm{i}} n_{0} m_{0}}{k_{\mathrm{t}}^{\prime \prime}\left(1+\frac{a}{m_{0}}\right)} \text {. }
$$

The monomer-consumption rate in the stationary part is described by the equation $-\mathrm{d} m / \mathrm{d} t=k_{\mathrm{p}}^{\prime} h_{4}$;

$$
\frac{\mathrm{d} x}{\mathrm{~d} \varphi}=-\frac{1}{m_{0}} \frac{\mathrm{d} m}{\mathrm{~d} \varphi}=\frac{k_{\mathrm{p}}^{\prime \prime} n_{4}}{m_{0}^{2}}=k_{\mathrm{p}}^{\prime \prime} \frac{k_{\mathrm{i}}}{k_{\mathrm{t}}^{\prime \prime}} \frac{n_{0}}{m_{0}+a},
$$

to give,

$$
k_{\mathrm{p}}^{\prime \prime}=\frac{\mathrm{d} x / \mathrm{d} \varphi}{k_{\mathrm{i}} / k_{\mathrm{t}}^{\prime \prime}\left(n_{0} / m_{0}+a\right)} .
$$

The value of $\mathrm{d} x / \mathrm{d} \varphi$ was calculated from the slopes of the linear parts of the kinetic curves in the $x^{2}-\varphi$ coordinate system (Figure 2a).

\section{Inhibition Stage}

If the values of initiation, propagation, and termination constants are used (Table III), it is easy to determine the ratio of $k_{\mathrm{dsc}} / k_{\mathrm{sc}}$,

$$
\frac{k_{\mathrm{dsc}}}{k_{\mathrm{sc}}}=b \frac{k_{\mathrm{t}}^{\prime \prime}}{k_{\mathrm{p}}^{\prime \prime} k_{\mathrm{i}}}=\frac{1.33 \times 0.16}{1.9 \times 10^{3} \times 6.9 \times 10^{-4}}=0.16 .
$$

This ratio shows that in the inhibition stage, the equilibrium is displaced toward the formation of a polymer complex with the catalyst. This is to be expected since polymer chains are known to be much stronger complexing agents than their monomer analogues. ${ }^{14}$

\begin{tabular}{|c|c|c|c|c|c|c|c|c|}
\hline \multirow{2}{*}{$\frac{[\mathrm{M}]_{0}}{\mathrm{mol1}^{-1}}$} & \multirow{2}{*}{$\frac{\left[\mathrm{H}_{2} \mathrm{O}\right]_{0}}{\mathrm{~mol} \mathrm{l}^{-1}}$} & \multirow{2}{*}{$\frac{\left[i-\mathrm{Bu}_{3} \mathrm{Al}\right]_{0}}{\mathrm{moll}^{-1}}$} & \multirow{2}{*}{$x$} & \multirow{2}{*}{$M_{n} \times 10^{-3}$} & \multirow{2}{*}{$\varphi_{\text {ind }}$} & \multirow{2}{*}{$\frac{k_{\mathrm{i}} \times 10^{4}}{\mathrm{mol1}^{-1} \min ^{-1}}$} & \multirow{2}{*}{$\frac{k_{\mathrm{t}}}{\min ^{-1}}$} & \multirow{2}{*}{$\frac{k_{\mathrm{p}} \times 10^{-}}{\min ^{-1}}$} \\
\hline & & & & & & & & \\
\hline 0.55 & 0.003 & 0.01 & 0.046 & 610 & - & 5.5 & - & 1.52 \\
\hline 0.55 & 0.003 & 0.01 & 0.129 & 610 & - & 7.3 & - & - \\
\hline 0.55 & 0.003 & 0.01 & 0.216 & 720 & - & 6.8 & - & - \\
\hline 0.55 & 0.003 & 0.01 & 0.265 & 714 & - & 7.1 & - & - \\
\hline 0.53 & 0.002 & 0.01 & 0.150 & 750 & 7.0 & 7.4 & 0.17 & - \\
\hline 0.53 & 0.002 & 0.01 & 0.250 & 760 & - & 7.5 & - & - \\
\hline 0.30 & 0.006 & 0.03 & - & - & 2.2 & - & 0.13 & 2.0 \\
\hline 0.50 & 0.006 & 0.03 & - & - & 3.75 & - & 0.16 & 2.2 \\
\hline 1.0 & 0.006 & 0.03 & - & - & 4.60 & - & 0.17 & 1.7 \\
\hline 0.55 & 0.003 & 0.02 & - & - & 8.50 & - & 0.16 & - \\
\hline \multirow[t]{2}{*}{0.273} & 0.0015 & 0.01 & - & - & - & - & - & 2.0 \\
\hline & & & & & & $6.9 \pm 0.3$ & $0.16 \pm 0.02$ & $1.9 \pm 0.3$ \\
\hline
\end{tabular}

Table III gives the values of the constants for the elementary reactions determined by using eq 1921. As expected, the propagation-rate constant is much higher than that of the initiation. This

Table III. Constants for elementary reactions determined for the polymerization of $\mathrm{MCMO}$ at $20^{\circ} \mathrm{C}$ with the $i-\mathrm{Bu}_{3} \mathrm{Al}-\mathrm{H}_{2} \mathrm{O}$ catalyst system 
explains the low degree of consumption of the catalyst in the initiation stage.

\section{CONCLUSIONS}

Consideration of the kinetics of the polymerization of MCMO under the influence of the $i$ $\mathrm{Bu}_{3} \mathrm{Al}-\mathrm{H}_{2} \mathrm{O}$ catalyst suggests that the polymerization occurs via the stage of preliminary formation of a complex of the monomer with active centres which in turn undergo decay by monomolecular mechanism. The slowing down of the rate of the process with conversion is due to the deactivation of the catalyst by the polymer. The kinetic scheme based on these concepts and its mathematical description has made possible the determination of rate constants for elementary reactions. The agreement between theoretical and experimental dependences confirms our mechanism for the polymerization of $\mathrm{MCMO}$ with the $i-\mathrm{Bu}_{3} \mathrm{Al}-\mathrm{H}_{2} \mathrm{O}$ catalyst system. Other kinetic schemes did not provide equations adequately describing the experimental kinetics. ${ }^{6}$

Acknowledgment. These experiments were partially carried out at the Centre of Molecular and Macromolecular Studies, Polish Academy of Sciences, in Prof. St. Penczek's laboratory. The authors are grateful to Prof. Penczek for the opportunity of carrying out these investigations and for his helpful comments on the results.

\section{REFERENCES}

1. J. Penczek, Ju. N. Sazanov, and St. Penczek, Makromol. Chem., 100, 156 (1967); St. Penczek and P. Kubisa, ibid., 130, 186 (1969).

2. G. P. Aleksiuk, E. B. Toporkova, L. V. Alferova, and V. A. Kropachev, Vysokomol. Soedin., Ser. A, 21, 2149 (1979).

3. T. Saegusa, H. Imai, and Sh. Matsumoto, J. Polym. Sci., A-1, 6, 459 (1969).

4. A. Storr, K. Jones, and A. W. Lanbengayer, J. Am. Chem. Soc., 90, 3173 (1968).

5. N. Ueyama, T. Araki, and H. Tani, Inorg. Chem., 12, 2218 (1973).

6. G. P. Aleksiuk, V. V. Shamanin, A. F. Podolsky, L. V. Alferova, and V. A. Kropachev, Vysokomol. Soedin., Ser. A, 21, 1425 (1979).

7. L. L. Burshtein, T. I. Borisova, and G. P. Michajlov, Vysokomol. Soedin., Ser. A, 4, 1479 (1962).

8. G. P. Aleksiuk, L. V. Alferova, and V. A. Kropachev, Vysokomol. Soedin., Ser. A, 21, N 12 (1979).

9. G. P. Aleksiuk, E. B. Toporkova, L. V. Alferova, and V. A. Kropachev, Vysokomol. Soedin., Ser. A, 18, 16 (1976).

10. N. S. Enikolopian, Usp. Chim., 36, 714 (1966).

11. I. I. Irzhak and N. S. Enikolopian, Dokl. Akad. Nauk SSSR, 185, 863 (1969).

12. Al. Al. Berlin, A. A. Saadian, and N. S. Enikolopian, Vysokomol. Soedin., Ser. A, 11, 1893 (1969).

13. A. A. Korotkov and A. F. Podolsky, Vysokomol. Soedin., Ser. A, 8, 332 (1966).

14. M. G. Kolomeer, E. V. Stovbun, V. F. Gachkovsky, and E. F. Vainstein, Dokl. Akad. Nauk SSSR, 212, 403 (1973). 